\title{
Cholangiocarcinoma Patient Outcome in Northeastern Thailand: Single-Center Prospective Study
}

\author{
Vor Luvira $^{1 *}$, Kasama Nilprapha ${ }^{1}$, Vajarabhongsa Bhudhisawasdi ${ }^{1}$, Ake \\ Pugkhem $^{1}$, Nittaya Chamadol ${ }^{2}$, Supot Kamsa-ard ${ }^{3}$
}

\begin{abstract}
Background: Cholangiocarcinoma is relatively rare worldwide. Most previous reports collected only patients with pathological diagnosis. In fact, however, many patients coming to hospital are diagnosed by clinical suspicion with radiologic imaging and receive treatment without histological confirmation. Real survival data and outcome of each treatment, especially for patients that do not have histologic confirmation, are lacking. In this study, therefore, we aimed to analyze the survival rates of CCA patients and the proportions of patients receiving different treatments. Materials and Methods: A total of 270 patients clinically suspected of CCA and visiting Srinagarind Hospital in May-July 2010, were prospectively followed until December 2014. After checking their clinical records, 163 of 270 patients were finally diagnosed as having $\mathrm{CCA}$, and the data of this group were analyzed for survival rate and received treatments. Results: Of the 163 patients, $96(58.9 \%)$ had intrahepatic, $56(34.4 \%)$ had perihilar and $11(6.7 \%)$ had distal CCA. The majority $[107(65.6 \%, 95 \%$ CI, 57.8-73.0)] received only supportive care. Overall median survival was 4 months (95\% CI, 3.3-4.7), and 2-years survival was only 8.1\% (95\% CI,4.5-12.9). However, the 4 year survival of the R0 resection group was $100 \%$. Conclusions: The present results show that the prognosis of CCA is very poor in North-east Thailand. Most CCA patients receive only treatment to alleviate symptoms due to their advanced stage of disease. Complete surgical resection at the early stage is the only treatment that significantly improves patient survival.
\end{abstract}

Keywords: Cholangiocarcinoma - treatment - surgical resection - survival rate

Asian Pac J Cancer Prev, 17 (1), 401-406

\section{Introduction}

The incidence of cholangiocarcinoma (CCA) varies worldwide with the highest incidence in Thailand, especially in Khon Kaen province, where the incidence of CCA is 44.3 and 17.6 per 100,000 for males and females, respectively. (Kamsa-ard, 2011) In the Srinagarind Hospital, Khon Kaen University, 661 patients were diagnosed as CCA during one year, from 2008-2009. (Cancer Unit, Faculty of Medicine, Khon Kaen University, 2009).

Definite diagnosis of CCA can be made after histopathological examination of the primary tumor, and most of previous clinical studies on CCA collected data retrospectively based on histo-pathological diagnosis. (International Association of Cancer Registries, 2015).

However, as a matter of fact, many patients came to our hospital were diagnosed as CCA only based on clinical suspicion with radiologic imagings. The patients were treated either with curative resection of tumor, or, inoperable cases, palliative therapy such as biliary drainage, biliary stent, chemotherapy and/or symptomatic treatment. (Khan, et al., 2012; Razumilava and Gores,
2014) In general, the latter group did not have histologic confirmation. The real survival data and outcome of each treatment, especially of patients who did not have histologic confirmation, are lacking.

The objectives of this study are to analyze the survival rate of CCA patients and the proportion of the patients who received curative or palliative treatments and also compare the survival outcomes.

Research question of the study: What is the real survival rate of CCA patients after diagnosis in Srinagarind Hospital?

Research objective of the study: $i$ ) To investigate the survival rate of cholangiocarcinoma after diagnosis in Srinagarind hospital. ii) To determine the proportion of the patients who received curative or palliative treatments. iii) To compare the survival outcomes of each treatment modalities.

\section{Materials and Methods}

\section{Overview of the study design}

This study is a cohort study. The patients who visited Srinagarind Hospital in May to July 2010 with clinical 
suspicion of CCA due to problems of obstructive jaundice, hepatomegaly, palpable gall bladder, liver mass, suspected CCA from ultrasonography and metastatic cancer of unknown origin were included in this study. We found 270 suspected CCA patients and their initial data including demographic data, medical history, presenting symptoms, radiographic and clinical tumor data were recorded. They have been prospectively followed up by chart review, phone call, returned-mail and the search for the Khon Kaen Cancer Registry data up to 31 December 2014.The end point of the study for each patient was death. Those who were lost to follow up were considered as being censored.

Of 270 suspected patients, 107 patients were excluded because they have no imaging confirmation, or were diagnosed as hepatocellular carcinoma, other benign/ malignant liver and biliary tumor, cholelithiasis, infection/ inflammatory liver disease, liver metastasis, pancreatic cancer and liver parenchymal disease mainly based on $\mathrm{CT} / \mathrm{MRI}$ reports from radiologists and/or histological reports from pathologists. Finally, 163 patients who were diagnosed as CCA were included and additional data of the level of diagnosis, treatment data, operative data, pathological reports and death date were retrieved from the records, and these data were analyzed (Figure 1).

They were classified into 3 groups according to the AJCC 7th definition: intrahepatic, perihilar and distal bile duct. (Edge and Byrd, 2010) R0 resections were defined as those with no gross or microscopic tumor left behind, $\mathrm{R} 1$ resections as those with microscopically positive margins, and $\mathrm{R} 2$ resections as those within complete resection of gross tumors. A palliation was defined as surgical operations in which no major tumor resection was attempted and interventions were focused on biopsy and bile duct bypass. Survival length was measured from the date of first visit to death date or to the end of the study, 31 December 2014.

Cholangiocarcinoma (CCA) or bile duct cancer is a primary cancer originating in the biliary epithelial cell that arises from intrahepatic and extrahepatic but not including gallbladder and ampulla of Vater. (Edge and Byrd, 2010) Ethical considerations.

The present study was approved by the Institutional Review Board, IRB (HE531125), under the Office of Human Research Ethics, Khon Kaen University. All participants were informed about the objective of study before signing the consent form.

\section{Statistical analyses}

Description of baseline characteristics of study patients The percentages were used to describe the proportion of categories data. The mean with standard deviation (SD) was used to describe continuous variables. Survival curves were estimated by the Kaplan-Meier method. The log-rank test was used to compare the survival curve.

All statistical tests were two-sided with a significant level of 0.05 . No adjustment of alpha level was made for multiple testing. All statistical analyses were implemented using the Stata 10 (Stata Corp, College Station, TX, 2015).

\section{Data processing}

The data was entered into a computer by using Epidata. (Epidata Corp, 2015) The verification was performed with necessary correction including logical, range, and internal consistency checked using the Stata10 statistical software. (Stata Corp, College Station, TX, 2015).

\section{Results}

In the 3-month duration of this study, 163 patients were diagnosed CCA. They came to Srinagarind Hospital by referral $123(75 \%)$ and self check-in 40 (25\%).The majority of referral patients were from the provincial hospitals $95(58.3 \%)$ and the rest from district hospitals outside Khon Kaen 20 (12.3\%) and private hospitals 8

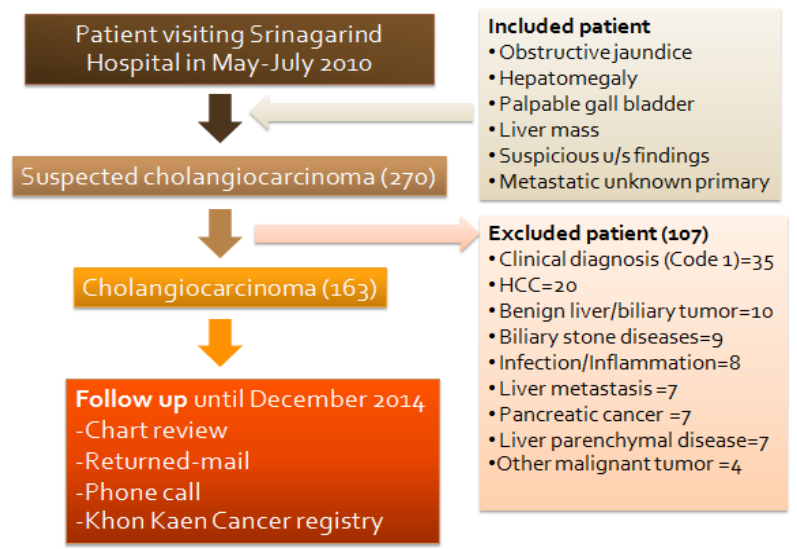

Figure 1. Flow Chart of the Selection of Patients Included in the Study

Table 1. Characteristics of Patients and Signs and Symptoms at Presentation in Relation to Tumor Location

\begin{tabular}{|c|c|c|c|c|c|c|}
\hline & & $\begin{array}{c}\text { Total } \\
\mathrm{n}=163\end{array}$ & $\begin{array}{c}\text { Intrahepatic } \\
n=96\end{array}$ & $\begin{array}{c}\text { Perihilar } \\
\mathrm{n}=56\end{array}$ & $\begin{array}{l}\text { Distal } \\
\mathrm{n}=11\end{array}$ & $\mathrm{P} *$ \\
\hline Median age & & $62 \pm 8.8$ & $60.5 \pm 8.9$ & $62.0 \pm 8.9$ & $67.0 \pm 6.4$ & 0.047 \\
\hline \multirow[t]{2}{*}{ Sex } & Male & $110(67.5 \%)$ & $65(67.7 \%)$ & $40(71.4 \%)$ & $5(45.5 \%)$ & \multirow[t]{2}{*}{0.24} \\
\hline & Female & $53(32.5 \%)$ & $31(32.3 \%)$ & $16(28.6 \%)$ & $6(54.5 \%)$ & \\
\hline \multirow[t]{8}{*}{ Signs \& Symptoms } & Abdominal pain & $113(69.3 \%)$ & $71(74.0 \%)$ & $35(62.5 \%)$ & $7(63.6 \%)$ & 0.31 \\
\hline & Jaundice & $73(44.8 \%)$ & $16(16.7 \%)$ & $48(85.7 \%)$ & $9(81.8 \%)$ & $<0.001$ \\
\hline & Fever & $28(17.2 \%)$ & $12(12.5 \%)$ & $15(26.8 \%)$ & $1(9.1 \%)$ & 0.025 \\
\hline & Weight loss & $77(47.2 \%)$ & $41(42.7 \%)$ & $28(50.0 \%)$ & $8(72.7 \%)$ & 0.07 \\
\hline & Hepatomegaly & $88(54.0 \%)$ & $54(56.3 \%)$ & $31(55.4 \%)$ & $3(27.3 \%)$ & 0.17 \\
\hline & Virchow & $11(6.7 \%)$ & $10(10.4 \%)$ & $1(1.8 \%)$ & 0 & 0.09 \\
\hline & Rectal shelf & $3(1.8 \%)$ & $1(1.0 \%)$ & $2(3.6 \%)$ & 0 & 0.55 \\
\hline & Palpable GB & $8(4.9 \%)$ & $1(1.0 \%)$ & $5(8.9 \%)$ & $2(18.2 \%)$ & 0.01 \\
\hline
\end{tabular}

*P values compare variables among patients with the 3 tumor locations; GB indicates gall bladder 
$(4.9 \%)$.

Among 163 patients, 137 patients (84\%) were diagnosed based on clinical investigation (level 2), $127(78 \%)$ were by radiologic imaging and10 (6\%) by laparotomy. Diagnosis by cytology (level 5) was $1(1 \%)$ case, by histology of metastatic site (level 6) was 11 (7\%) cases and by histology of primary tumor (level 7) was 14 $(8 \%)$ cases. The imaging modalities used for diagnosis were: CT: 134 (82.2\%), MRI/MRCP: 24 (14.7\%), ultrasonography: 3 (1.8\%) and ERCP: 2 (1.2).

Of 163 patients, $96(59 \%)$ were intrahepatic, 56 (34\%) were perihilar and $11(7 \%)$ were distal CCA. Characteristics of the patients and signs/symptoms at presentation are summarized in Table 1 .

Overall, the median age was $62 \pm 8.8$ years, and the patients with distal CCA were significantly older than the others $(\mathrm{P}=0.047)$. The patients were predominantly male with the $\mathrm{M} / \mathrm{F}$ ratio of about $2: 1$. The most common presenting symptom was abdominal pain, which was seen in $113(69.3 \%)$ cases. Jaundice was more frequently $(\mathrm{P}<0.001)$ seen in perihilar and distal CCA than in intrahepatic CCA. Fever also was more likely $(\mathrm{P}=0.025)$ to present in perihilar and distal CCA than in intrahepatic CCA.

Laboratory data in relation to tumor location are shown in Table 2. In accordance with the symptoms and signs, perihilar and distal CCA had higher total bilirubin $(\mathrm{P}<0.001)$ than did intrahepatic CCA. Conversely, perihilar and distal CCA had lower albumin level

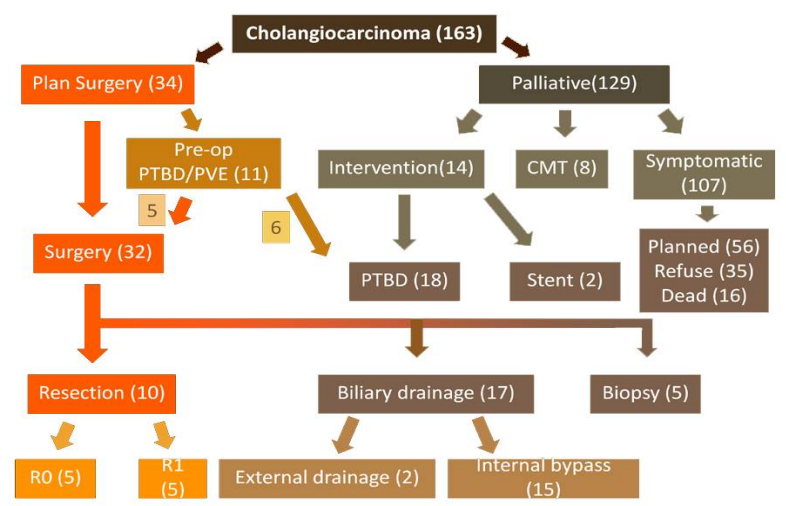

Figure 2. The Flow Chart Demonstrating Treatment Options for CCA
Cholangiocarcinoma Patient Outcome in North-eastern Thailand $(\mathrm{P}=0.004)$ than intrahepatic CCA. Overall, 97 patients (78.8\%) had elevated CA19-9 and 55 (44.7\%) of them were above $1000 \mathrm{IU} / \mathrm{L}$. However, elevation of CEA level was seen in $46(41.1 \%)$ patients, the frequency being lower than that of CA19-9. Using TNM staging, 100 patients $(61.3 \%)$ were in the stage IV, whereas $34(20.8 \%)$ were in the early stage.

The patients were received different treatment options according to the staging, resectability and performance status. The lines of treatments are shown in Figure 2. In this study, the patients were classified into 4 main groups according to the treatments they received: 10 $(6.1 \%)$ had curative resection including $5(3.1 \%)$ each of R0 R1 resection, but no R2;37 (22.7\%) received biliary drainage, and 9 (5.5\%)had chemotherapy; 107 (65.6\%) had symptomatic treatment. In relation to the location of CCA, palliative procedure (or biliary drainage) was much more frequent $(\mathrm{P}<0.001)$ in perihilar and distal CCA due to biliary obstruction than in intrahepatic CCA. Intrahepatic CCA patients were mainly received just symptomatic treatment $(\mathrm{P}<0.001)$.

The number of patients sorted by treatments in relation to tumor location are given in Table 3 . The largest group was the patients received symptomatic treatment, which can be divided into the following categories;56 patients $(52.3 \%)$ received only planned symptomatic treatment, 16 (15.0\%) died before receiving treatment and 35 (32.7\%) refused treatment intervention. The patients refused for treatments included $28(26.1 \%)$ of refusing surgical resection, $4(3.7 \%)$ of refusing percutaneous biliary drainage (PTBD) and 3 (2.8\%) of refusing chemotherapy or liver biopsy.

The results of 2 years follow-up for all patients are summarized in Figure 3.Overall median survival was 4 months (95\% CI, 3.3-4.7), 1-year survival was $14.1 \%$ (95\% CI, 9.3-19.9) and 2-year survival was 7.3\% (95\% CI, 3.9-12.0).

When the patients were divided into 3 groups according to their tumor locations, the median survival of intrahepatic, perihilar and distal CCA patients were 4 months (95\% CI, 4.3-4.7), 4 months (95\% CI, 2.5-5.5) and 5 months (95\% CI, 4.0-6.0), respectively. There was no statistically significant difference in median survival among tumor location groups $(\mathrm{P}=0.93)$. (Figure 4.)

Table 2. Laboratory Data and Tumor Marker in Relation to Tumor Location

\begin{tabular}{|c|c|c|c|c|c|c|}
\hline & & $\begin{array}{c}\text { Total } \\
\mathrm{n}=163\end{array}$ & $\begin{array}{c}\text { Intrahepatic } \\
n=96\end{array}$ & $\begin{array}{c}\text { Perihilar } \\
\mathrm{n}=56\end{array}$ & $\begin{array}{l}\text { Distal } \\
\mathrm{n}=11\end{array}$ & P value* \\
\hline \multirow[t]{7}{*}{ Laboratory data } & INR & $1.56 \pm 0.96$ & $1.38 \pm 0.70$ & $1.79 \pm 1.22$ & $1.36 \pm 0.48$ & 0.13 \\
\hline & $\mathrm{TB}(\mathrm{mg} / \mathrm{dL})$ & $10.2 \pm 12.0$ & $4.6 \pm 9.4$ & $17.4 \pm 10.8$ & $17.2 \pm 13.1$ & $<0.001$ \\
\hline & $\mathrm{Alb}(\mathrm{g} / \mathrm{dL})$ & $3.7 \pm 0.8$ & $3.9 \pm 0.8$ & $3.5 \pm 0.6$ & $3.5 \pm 0.7$ & 0.004 \\
\hline & $\mathrm{Cr}(\mathrm{mg} / \mathrm{dL})$ & $1.0 \pm 0.6$ & $1.1 \pm 0.8$ & $0.9 \pm 0.4$ & $0.9 \pm 0.3$ & 0.45 \\
\hline & ALT (IU/L) & $67.5 \pm 62.0$ & $58.7 \pm 64.3$ & $80.4 \pm 57.6$ & $71.1 \pm 59.0$ & 0.16 \\
\hline & AST (IU/L) & $81.8 \pm 75.2$ & $70.0 \pm 82.8$ & $98.2 \pm 64.3$ & $91.5 \pm 50.0$ & 0.11 \\
\hline & $\operatorname{ALP}(\mathrm{IU} / \mathrm{L})$ & $375.2 \pm 262.9$ & $313.3 \pm 253.1$ & $485.9 \pm 258.6$ & $314.9 \pm 195.8$ & 0.001 \\
\hline \multirow[t]{4}{*}{ †CA 19-9 (IU/L) } & $<0.6$ & $11(8.9 \%)$ & $7(9.5 \%)$ & $4(10.3 \%)$ & 0 & 0.29 \\
\hline & $0.6-36$ & $15(12.2 \%)$ & $5(6.8 \%)$ & $8(20.5 \%)$ & $2(20 \%)$ & \\
\hline & $37-1000$ & $42(34.1 \%)$ & $28(37.8 \%)$ & $12(30.8 \%)$ & $2(20 \%)$ & \\
\hline & $>1000$ & $55(44.7 \%)$ & $34(45.9 \%)$ & $15(38.5 \%)$ & $6(60 \%)$ & \\
\hline \multirow[t]{2}{*}{$\dagger \mathrm{CEA}(\mu \mathrm{g} / \mathrm{L})$} & $<22$ & $66(58.9 \%)$ & $36(54.5 \%)$ & $27(75.0 \%)$ & $3(30.0 \%)$ & 0.025 \\
\hline & $>22$ & $46(41.1 \%)$ & $30(45.5 \%)$ & $9(25.0 \%)$ & $7(70.0 \%)$ & \\
\hline
\end{tabular}


Table 3. Treatments in Relation to Tumor Location

\begin{tabular}{|c|c|c|c|c|c|c|}
\hline & & $\begin{array}{c}\text { Total } \\
\mathrm{n}=163\end{array}$ & $\begin{array}{c}\text { Intrahepatic } \\
n=96\end{array}$ & $\begin{array}{c}\text { Perihilar } \\
\mathrm{n}=56\end{array}$ & $\begin{array}{l}\text { Distal } \\
\mathrm{n}=11\end{array}$ & $\mathrm{P}^{*}$ \\
\hline Surgery & & $32(19.6 \%)$ & $11(11.5 \%)$ & $16(28.6 \%)$ & $5(45.5 \%)$ & 0.003 \\
\hline \multirow[t]{4}{*}{ Resection } & & $10(6.1 \%)$ & $6(6.3 \%)$ & $4(7.1 \%)$ & 0 & 0.07 \\
\hline & R0 & $5(3.1 \%)$ & $3(3.1 \%)$ & $2(3.6 \%)$ & 0 & \\
\hline & $\mathrm{R} 1$ & $5(3.1 \%)$ & $3(3.1 \%)$ & $2(3.6 \%)$ & 0 & \\
\hline & $\mathrm{R} 2$ & 0 & 0 & 0 & 0 & \\
\hline \multirow[t]{2}{*}{ Palliative surgery } & Biliary drainage & $17(10.4 \%)$ & $1(1.0 \%)$ & $11(19.6 \%)$ & $5(45.5 \%)$ & 0.02 \\
\hline & Biopsy/celiac block & $5(3.1 \%)$ & $4(4.2 \%)$ & $1(1.8 \%)$ & 0 & \\
\hline \multirow[t]{2}{*}{ Pre-operative procedure } & PVE & $2(1.2 \%)$ & 0 & $2(3.6 \%)$ & 0 & 0.008 \\
\hline & PTBD & $11(6.7 \%)$ & 0 & $11(19.6 \%)$ & 0 & \\
\hline Chemotherapy & & $14(8.6 \%)$ & $12(12.5 \%)$ & $2(3.6 \%)$ & 0 & 0.095 \\
\hline \multirow[t]{2}{*}{ Adjuvant } & 5FU+MMC & $3(1.8 \%)$ & $2(2.1 \%)$ & $1(1.8 \%)$ & 0 & \\
\hline & Capecitabine & 0 & 0 & 0 & 0 & \\
\hline \multirow[t]{3}{*}{ Palliative } & 5FU+MMC & $4(2.5 \%)$ & $4(4.2 \%)$ & 0 & 0 & \\
\hline & Capecitabine & $5(3.1 \%)$ & $5(5.2 \%)$ & 0 & 0 & \\
\hline & Unknown & $2(1.2 \%)$ & $1(1.0 \%)$ & $1(1.0 \%)$ & 0 & \\
\hline \multirow[t]{4}{*}{ Palliative procedure } & & $37(22.6 \%)$ & $4(4.2 \%)$ & $27(48.2 \%)$ & $6(54.5 \%)$ & $<0.001$ \\
\hline & $\begin{array}{l}\text { PTBD, external } \\
\text { biliary drainage }\end{array}$ & $20(12.2 \%)$ & $3(3.1 \%)$ & $16(28.6 \%)$ & $1(9.1 \%)$ & 0.25 \\
\hline & $\begin{array}{l}\text { Enterobiliary } \\
\text { bypass }\end{array}$ & $15(9.1 \%)$ & $1(1.0 \%)$ & $9(16.1 \%)$ & $5(45.5 \%)$ & \\
\hline & ERCP, stent & $2(1.2 \%)$ & 0 & $2(3.6 \%)$ & 0 & \\
\hline \multirow{4}{*}{$\begin{array}{l}\text { Symptomatic } \\
\text { treatment }\end{array}$} & & $107(65.6 \%)$ & $77(80.2 \%)$ & $25(44.6 \%)$ & $5(45.5 \%)$ & $<0.001$ \\
\hline & At Srinagarind & $34(20.9 \%)$ & $22(22.9 \%)$ & $10(17.9 \%)$ & $2(18.2 \%)$ & \\
\hline & Referred & $35(21.5 \%)$ & $29(30.2 \%)$ & $5(8.9 \%)$ & $1(9.1 \%)$ & \\
\hline & Home care & $38(23.3 \%)$ & $26(27.1 \%)$ & $10(17.9 \%)$ & $2(18.2 \%)$ & \\
\hline
\end{tabular}

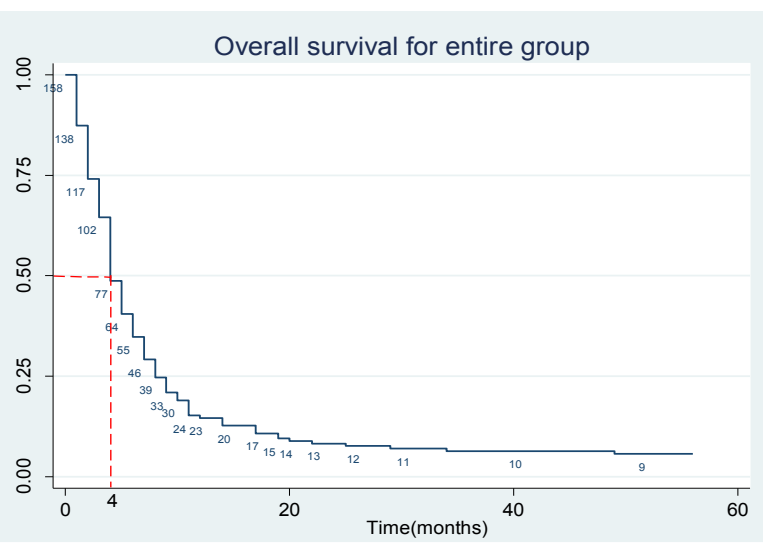

Figure 3. Overall Survival of CCA Patients after Diagnosis in Srinagarind Hospital

When the survival of each treatment group were compared, the surgical resection group had best 2-year survival, 70\% (95\% CI, 32.9-89.3), $\mathrm{P}<0.001$. Others had similar median survival without statistical difference: biliary drainage 5 months (95\% CI, 3.3-6.7), chemotherapy 6 months (95\% CI, 3.9-8.1), symptomatic treatment 4 months (95\% CI, 3.3-4.7), $\mathrm{P}=0.37$ as shown in Figure 5.

Among the patients undergone surgery, each operative procedure had different survival outcome $(\mathrm{P}<0.001)$. 4-year survival of R0 resection was $100 \%$, whereas that of $\mathrm{R} 1$ resection was $20 \%(0.8-58.2)$ with the median survival of 8 months (95\% CI, 0.5-15.5).That is, the R0 and R1 resection had different survival (100\% and 20\%), this difference was statistically significant $(\mathrm{P}<0.001)$. The median survival of enterobiliary drainage was 5 months (95\% CI, 3.7-6.3) and that of biopsy/celiac block was 4 months (95\% CI, 3.1-6.9). Compare to other procedures,

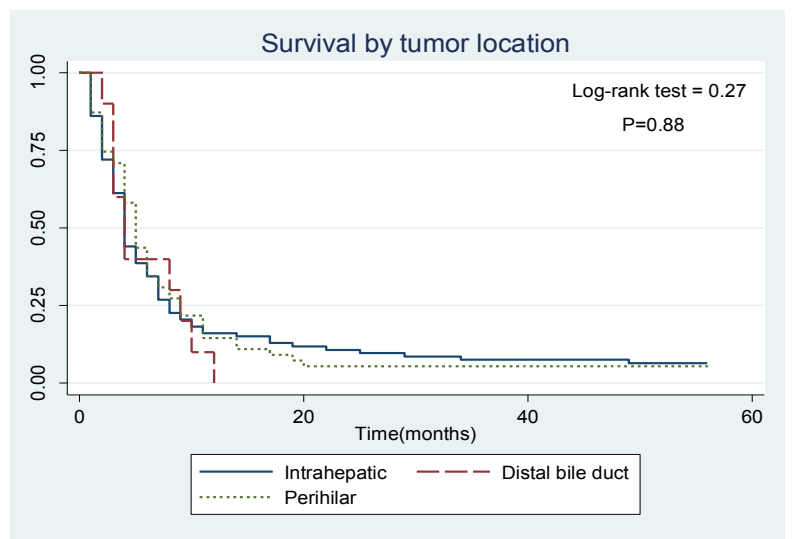

Figure 4. Survival Rate of CCA Patients with Different Tumor Locations after Diagnosis in Srinagarind Hospital

R0 and R1 resection significantly improved survival outcome $(\mathrm{P}<0.001)$. Although the 2-year survival of $\mathrm{R} 1$ was worse than R0 resection, R1 still had significantly better survival than biliary drainage and biopsy/celiac block $(\mathrm{P}=0.03)$. The median survival of each biliary drainage procedure are; external biliary drainage (PTBD) 5 months (95\% CI, 3.3-6.7), enterobiliary bypass 5 months (95\% CI, 2.5-7.5) and biliary stent 7 months, with no significant difference among them $(\mathrm{P}=0.20)$. (Figure 6.)

In symptomatic treatment group, the patients were divided into 3 subgroups depending on the type of treatment; those who received planned symptomatic treatment, those who died before planned treatment, and those who refused treatment. The survival rate of each symptomatic treatment group revealed statistically significant difference in median survival among them (Figure 7). The patients who died before definite treatment 
had median survival 2 months. Patients who refused treatment had median survival 6 months $(95 \% \mathrm{CI}, 4.8-$ 7.2), significant longer than that [4 months $(95 \%$ CI, 3.34.7), $\mathrm{P}=0.04$ ] of the planned only symptomatic treatment groups. There was no statistical difference in the median survival for each intervention they refused $(\mathrm{P}=0.53)$.

Also there is no statistical difference in the median survival among the places (Srinagarind Hospital, referral hospital or home care) where patients were symptomatically treated $(\mathrm{P}=0.66)$. During 4 years followup period, there were 3 patients who were diagnosed as

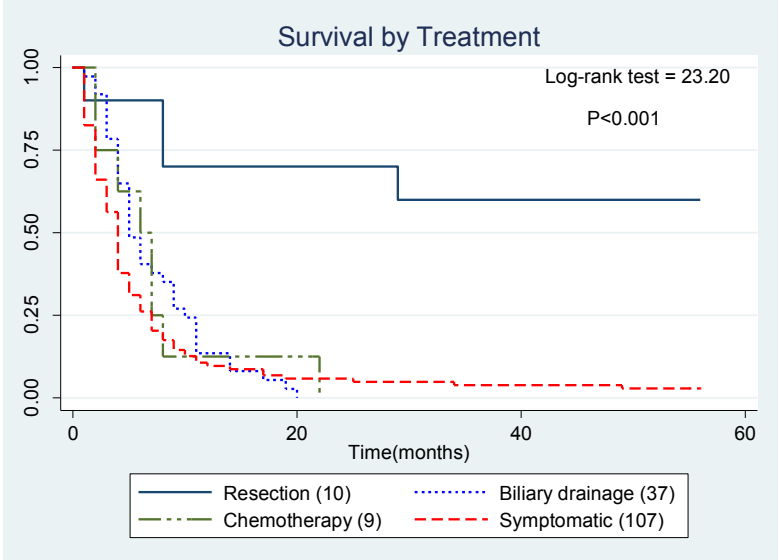

Figure 5. Survival Rate of CCA Patients Treated with Various Modalities

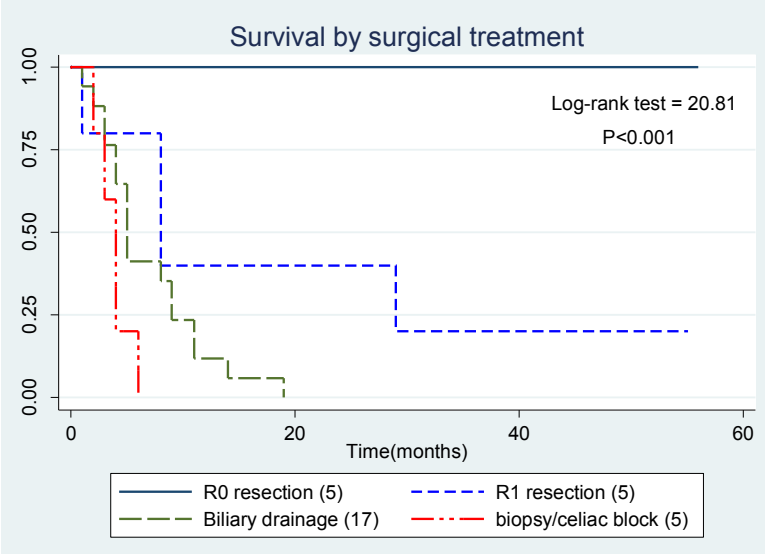

Figure 6. Survival Rate of CCA Patients after Various Surgical Treatments

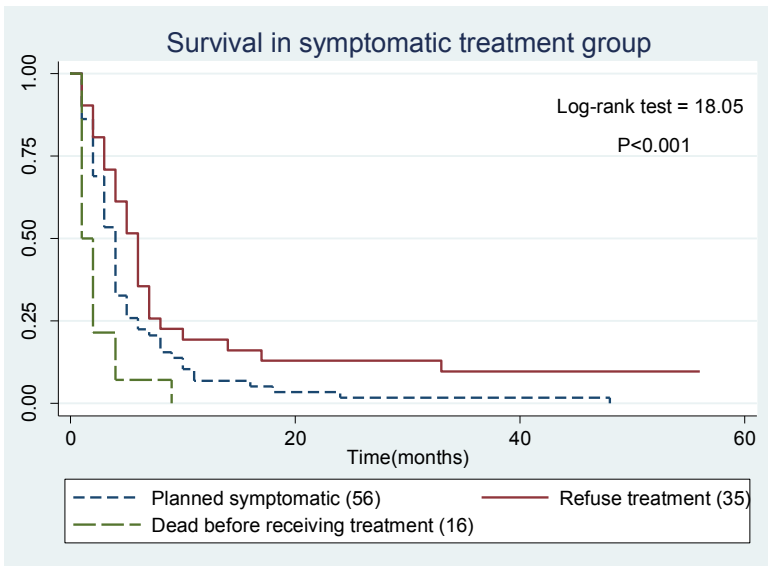

Figure 7. Overall Survival Experience of CCA by Type of Non-curative Treatment intraductal CCA under CT imaging. They refused surgical resection and received only symptomatic treatment, and 2 of 3 still alive at the end of this study.

\section{Discussion}

CCA is highly endemic in Khon Kaen province, Thailand. (Kamsa-ard, et., 2011) In this study, we collected 163 patients diagnosed CCA within 3 months of time. Diagnosis was mainly made from radiologic imaging such as CT or MRI/MRCP (84\%) and only few cases were confirmed by histopathology of a primary tumor $(8.6 \%)$. This tendency was similar to the previous report in Khon Kaen. (Kamsa-ard, et al., 2011) When the patients were classified according to the tumor location, intrahepatic CCA was more frequent than perihilar and distal CCA. The location of CCA varies among the countries. In Malaysia, (Yusoff, et al., 2012) and United States, (DeOliveira, et al., 2007) perihilar CCA was reported to be a major type. In Greece, (Alexopoulou, et al., 2008) the number of intrahepatic and perihilar CCA patients were almost equal. Like our results, intrahepatic type is dominant in Korea, (Park, et al., 2009) suggesting the close association of intrahepatic CCA with liver-fluke infection.

Median age of the patients in this study was comparable with the previous report in Khon Kaen, (Kamsa-ard, et al., 2011) and is slightly younger than that of CCA patients in western countries. (DeOliveira, et al., 2007; Alexopuolou, et al., 2008) Most of the patients in this study presented with abdominal pain. Jaundice and fever were predominantly seen in perihilar and distal CCA patients in association with the rise of TB and ALP which reflect the nature of tumors that cause obstructive jaundice. As many as $78.8 \%$ of the patients had elevated CA19-9, which is associated with poor prognosis or advanced disease. In contrast, CEA elevation was fewer, possibly be due to slightly lower CEA accuracy than CA19-9. (Qin, et al., 2004).

In this study, the majority ( $65.6 \%)$ of the patients were treated only with symptomatic treatment, and the curative resection was performed only for $6.1 \%$ of the patients. We found that most of the patients were already in stage IV or unresectable at their first visit. Thus, those patients were advised to have symptomatic treatment and histological confirmation was not always obtained. From the referral data, a number of patients were referred from district hospitals outside Khon Kaen, quite far and difficult to reach our hospital. Some of them came to our hospital only when they developed unbearable symptoms such as severe cachexia, severe abdominal pain, that imply the late stage of the disease. (Carriaga and Henson, 1995) The duration of abdominal pain until first hospital visitation was much longer than that of jaundice. It took approximately 1 month duration until reached definite diagnosis and treatment. In fact, $15 \%$ of patients died before receiving treatment.

The overall survival was very poor, 4 months in median survival and $7.3 \%$ 2-year survival, which are comparable with the survival of CCA in other Asian countries. (Park, et al., 2009; Yusoff, et al., 2012) This is because patients mostly received only symptomatic treatment. Curative resection gave much better survival 


\section{Vor Luvira et al}

outcome by both $\mathrm{R} 0$ and $\mathrm{R} 1$ resection. $\mathrm{R} 0$ resection provide the best treatment, 4-year survival reached $100 \%$. Other palliative options including biliary drainage gave no significant improvement on the survival rate. We noticed that in chemotherapy group, the median survival was slightly longer than symptomatic treatment and palliative intervention, although statistically not significant. Since the sample size of chemotherapy group was too small, further study using larger size of group is necessary. In symptomatic treatment group, we found the significant difference in planned only symptomatic treatment and refused surgery group. This can imply that $33 \%$ of the planned symptomatic treatment group may be potentially curable especially the patient with intraductal tumor who received only symptomatic treatment and had the long survival.Thus, patient education about risk-benefit of the operation may be essential to improve the survival outcome.

This study still has some limitations such as unequal number of patients in each group with very small number in some groups, which might cause some statistic errors. Longer follow up and more large number of inclusion of patients is needed to complete the survival outcome and improve the accuracy of the results, especially in surgical resection groups. Diagnosis using CT and/or MRI imaging may not be definite but we have to depend on them, because tissue sampling for diagnosis from obviously unresectable cases seem to be too invasive. Although there are some limitations as described above, this study gives the informative data of the current situation of CCA in Khon Kaen and provides the initial data for improving the CCA treatment system in future.

\section{Acknowledgements}

This study was granted by the Faculty of Medicine, Khon Kaen University, Thailand (KKU).The authors would like to acknowledge (a) Prof. Yukifumi Nawa for editing the manuscript via Publication Clinic KKU, Thailand, (b) the KKU Cancer Unit staffs for their assistance for data management, and (c) the Surgery Department officers for their careful data collection and follow up of the patients.

\section{References}

Alexopoulou A, Soultati A, Dourakis SP, et al (2008). Cholangiocarcinoma: A 7-year experience at a single center in Greece. World J Gastroenterol, 14, 6213-7.

Cancer Unit, Faculty of Medicine, Khon Kaen University (2009). Hospital based tumor registry: statistical report 2008, Khon Kaen: Thailand; 2009.

Carriaga MT and Henson DE (1995) Liver gallbladder extrahepatic bile ducts and pancreas. Cancer, 75, 171-90.

DeOliveira ML, Cunningham SC, Cameron JL, et al (2007): thirty-one-year experience with 564 patients at a single institution. Ann Surg, 245, 755-62.

Edge SB, Byrd DR (2010) AJCC Cancer staging manual. 7th ed. 2010. Springer-Verlag New York.

EpiData Software [homepage on the Internet]. [update 2015 January 1; cited 2015 Jan] Available from: http://www. epidata.dk
International Association of Cancer Registries [homepage on the Internet]. Lyon: [update 2015 January 1; cited 2015 Jan]. Available from: http://www.iacr.com.fr.

Kamsa-ard S, Wiangnon S, Suwanrungruang K, et al (2011). Trends in liver cancer incidence between 1985 and 2009 Khon Kaen Thailand: cholangiocarcinoma. Asian Pac J Cancer Prev, 12, 2209-13.

Khan SA, Davidson BR, Goldin RD, et al (2012). Guidelines for the diagnosis and treatment of cholangiocarcinoma. Gut, 61, 1657-69.

Park J, Kim M-H, Kim K-P, et al (2009). Natural history and prognostic factors of advanced cholangiocarcinoma without surgery chemotherapy or radiotherapy: a large-scale observational study. Gut Liver, 3, 298-305.

Qin X-L, Wang Z-R, Shi J-S, et al (2004). Utility of serum CA19-9 in diagnosis of cholangiocarcinoma: in comparison with CEA. World J Gastroenterol, 10, 427-32.

Razumilava N and Gores GJ (2014). Cholangiocarcinoma. Lancet, 383, 2168-79.

Stata I Data Analysis and Statistical Software [homepage on the Internet]. [update 2015 January 1; cited 2015 Jan] Available from: http://www.stata.com.

Yusoff AR, Razak MMA, Yoong BK, et al (2012). Survival analysis of cholangiocarcinoma: a 10 -year experience in Malaysia. World J Gastroenterol, 18, 458-65. 